\title{
Die Reidbyfinanzen
}

auf Grund ber

\section{Reform von 1919/20}

Bon

Dr. (Grwin Respondek

Gllfsarbeiter im Rethsftnanzminifterium

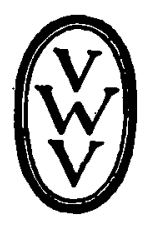

Berlin und $\mathfrak{L}$ eipzig 1921

Vereinigung wiffen Walter be Gruyter \& $\mathcal{C}_{0}$.

pormals 5. J. Göjđen'iche Werlagshandlung - J. Guttentag, Berlagg:

budbandlung - Georg Reimer - Rair J. Trübner - Vett \& Comp. 
Mofberg'fde Budbrudetei, Leipzig. 